Cahiers $d u$ MONDE RUSSE

\section{Cahiers du monde russe}

Russie - Empire russe - Union soviétique et États indépendants

$43 / 4 \mid 2002$

Intellectuels et intelligentsia

\title{
Sheila Fitzpatrick, Yuri Slezkine, eds, In the shadow of revolution
}

Martine Mespoulet

\section{OpenEdition \\ Journals}

Édition électronique

URL : https://journals.openedition.org/monderusse/4026

DOI : 10.4000/monderusse.4026

ISSN : $1777-5388$

Éditeur

Éditions de l'EHESS

Édition imprimée

Date de publication : 30 décembre 2002

Pagination : 717-718

ISBN : 2-7132-1796-2

ISSN : $1252-6576$

Référence électronique

Martine Mespoulet, "Sheila Fitzpatrick, Yuri Slezkine, eds, In the shadow of revolution », Cahiers du monde russe [En ligne], 43/4 | 2002, mis en ligne le 17 juin 2009, consulté le 03 septembre 2022. URL : http://journals.openedition.org/monderusse/4026 ; DOI : https://doi.org/10.4000/monderusse.4026

Ce document a été généré automatiquement le 3 septembre 2022

Tous droits réservés 


\title{
Sheila Fitzpatrick, Yuri Slezkine, eds, In the shadow of revolution
}

\author{
Martine Mespoulet
}

\section{RÉFÉRENCE}

Sheila FITZPATRICK, Yuri SLEZKINE, eds, In the shadow of revolution. Life stories of Russian women from 1917 to the Second World War. Princeton, Princeton University Press, 2000, $443 \mathrm{p}$.

1 L'ouvrage In the shadow of revolution, dirigé par Sheila Fitzpatrick et Yuri Slezkine, rassemble trente-six récits de vie de femmes. En réalité, il s'agit plutôt de tranches de vie, car celles-ci racontent une portion de leur vie entre 1917 et 1939, période clé de la construction de l'Union soviétique. Elles sont nombreuses, toutefois, à commencer leur récit en donnant quelques informations sur leur vie ou celle de leur famille avant la révolution d'Octobre, enrichissant ainsi notre compréhension de leur expérience de la révolution et des deux décennies qui suivirent. Les quelques lignes rédigées par les deux éditeurs pour présenter l'auteur de chaque texte contribuent également à mettre son propos en perspective.

2 Le livre est organisé en trois parties. Une première série de textes concerne l'année 1917 et la période de la guerre civile. Une deuxième section est consacrée aux années 1920, années de la NEP mais aussi de la mise en place du premier plan quinquennal et de la collectivisation. La dernière partie est centrée sur les années 1930. Sheila Fitzpatrick et Yuri Slezkine justifient leur choix d'arrêter la période explorée juste avant la Seconde Guerre mondiale par le fait que celle-ci a représenté une réelle rupture dans la vie de beaucoup de femmes soviétiques.

3 La diversité des situations rend la lecture de ce livre passionnante. Vivant en Union soviétique ou émigrées, habitant Moscou ou une ville de province, mariées ou vivant seules, intellectuelles, aristocrates, ouvrières ou paysannes, activistes politiques ou opposantes au régime, toutes ces femmes portent un regard sur les principaux 
événements de cette période à la lumière de leur propre expérience sociale, «à l'ombre de la révolution", ou de celle de leurs proches. La variété des documents présentés concourt aussi à enrichir ce tableau d'ensemble. Qu'il s'agisse de textes de littérature, d'extraits de mémoires, de récits autobiographiques, d'entretiens, de dossiers personnels ou de lettres à un éditeur, tous ces témoignages font resurgir des réactions et des attitudes d'individus face aux moments clés de cette période ou face à divers projets symboliques, comme la construction de la ville de Komsomolsk, par exemple.

Le contexte et la forme de l'écriture de ces différents récits doivent être pris en compte pour guider leur lecture. Dans leurs deux textes d'introduction, Sheila Fitzpatrick et Yuri Slezkine rappellent l'usage politique et social, dans les années 1920 et 1930, du récit autobiographique, de la confession publique, des lettres adressées à un journal ou à une revue, pour attirer notre attention sur la forme codifiée de leur facture et la distance nécessaire pour les interpréter. Néanmoins, au-delà des règles et du style de ce genre soviétique du récit de vie, les textes rassemblés ici livrent beaucoup d'éléments sur la vie quotidienne, l'attitude et les sentiments de citoyennes ordinaires et des personnes qu'elles ont côtoyées.

Car c'est bien une lecture de l'histoire de cette période tumultueuse à la lumière de l'expérience sociale des femmes qui intéresse avant tout les deux éditeurs de ce livre. La révolution devait être porteuse d'émancipation pour celles-ci. La diversité des cas et des situations offerte permet de mieux appréhender la manière dont les femmes qui parlent ici se sont approprié ou non les nouvelles possibilités offertes dans leur travail, ou dans la vie sociale en général, les contraintes qui ont pesé sur elles, leur propre appréciation de cette période. Ce corpus de textes fournit des indices sur la façon dont elles ont construit leur chemin ou interprété leur vie au milieu des bouleversements politiques et sociaux, de la violence et de la profonde transformation des hiérarchies sociales.

Le système d'allocation de logements et d'accès aux biens, les formes d'expression de la liberté sexuelle pendant les années 1920 et l'instauration d'un nouvel ordre moral dans les années 1930, le rôle de l'éducation et de la formation dans les trajectoires de ces femmes, la manière dont leur promotion fut acceptée par leur famille, les accusations et les dénonciations au sein d'un collectif de travail ou d'un autre groupe sont des exemples, parmi d'autres, de situations racontées par ces femmes sur la base de leur propre expérience ou de celle de leurs proches. Dans un autre registre, les témoignages d'épouses de stakhanovistes et le regard qu'elles portent sur leur mari suggèrent une autre lecture de ce mouvement. L'engagement dans le travail de ces hommes érigés en héros semble intégré dans un projet conjugal de promotion sociale reposant sur une augmentation du niveau de consommation et l'acquisition des signes symboliques d'une nouvelle forme de réussite sociale, projet qui mobilisait les deux membres du couple.

7 Dans une société divisée et cloisonnée, l'accès aux privilèges et au pouvoir conditionne l'accès aux biens, mais aussi une représentation de la société en deux camps. La question de l'identité sociale prend alors une telle résonance pour les individus que certains masquent la leur pour échapper à toute forme de stigmate social, d'autres la revendiquent et en perfectionnent le mode d'expression en adoptant «un parler bolchevik ». Ces phénomènes ont déjà été étudiés dans différents travaux. L'intérêt de cet ouvrage est de donner à voir ces comportements en actes dans la vie quotidienne. 